\title{
FAKTOR-FAKTOR YANG BERHUBUNGAN DENGAN KEJADIAN PREEKLAMSIA PADA IBU HAMIL DI KABUPATEN KEDIRI JAWA TIMUR
}

\author{
Katmini $^{1}$, Febrina Dwi N ${ }^{2}$, Astri Yunita ${ }^{3}$ \\ 1,2,3 STIKes Bhakti Mulia Kediri \\ Diterima: 24 Oktober 2018 , Disetujui: 12 November 2018 \\ e-mail : Katminitini@gmail.com
}

\begin{abstract}
Background: The high MMR in 2015 is a big problem in Indonesia, which is 305 per 100,000 live births (Profile of Indonesian Population Results Supas, 2015). The Indonesian Demographic and Health Survey (2012) shows that MMR in Indonesia is still high at 359 per 100,000 KH. This rate is slightly decreased when compared to IDHS (1991) which is equal to 390 per 100,000 KH. The third goal of the Sustainable Development Goals is good health (Ministry of Health 2015), reducing MMR to 102 per 100,000 KH. Maternal mortality in 2010-2012 was caused by an enhancement in the incidence of preeclampsia, eclampsia and other factors, such as social problems, culture, lack of education, and economic problems. Method: The study was conducted at the Public Health assisted by Kediri Regency in April 2018. It used Quantitative research method by an Explanatory Study with the design of Case Control Study. The number of samples was 100 pregnant women from the Public Health in Kediri Regency. The independent variables were the age of pregnant women, education, employment, Body Mass Index and weight. The dependent variable was preeclampsia. The Primary data was conducted by interview using questionnaires and was supported by secondary data. And the data was analyzed by Bivariate Analysis with Chi Square using SPSS 22. Results. From the results of bivariate analysis using the chi square test, there was a relationship between the age of pregnant women $(O R=0.35 ; 95 \% C I=0.15$ to $0.80 ; p=0.012)$, parity $(O R=0.26 ; 95 \% C I=0.11$ to 0.62; $p=0.002)$, education level $(O R=0.15 ; 95 \% C I=0.06$ to $0.38 ; p=<0.001)$ and employment $(O R=8.66 ; 95 \% C I=3.46$ to $21.65 ; p=<0.001)$ with preeclampsia. There was no correlation between BMI $(O R=1.06 ; 95 \% C I=0.47$ to $2.38 ; p=0.870), B B(O R$ $=0.93 ; 95 \% C I=0.41$ to $2.09 ; p=0.869)$, with preeclampsia. Conclusion. There is a correlation between the age of pregnant women, parity, education level and occupation with preeclampsia. Other variables which are not related to the case of preeclampsia are Body Mass Index and weight.
\end{abstract}

Keywords: Education, Employment, Age, BMI, BB, Preeclampsia Level

\section{PENDAHULUAN}

AKI yang tinggi tahun 2015 merupakan masalah yang besar di Indonesia, yaitu 305 per 100.000 kelahiran hidup (Profil Penduduk Indonesia Hasil Supas, 2015). Kematian ibu menurut World Health Organization (AKI, 2014), adalah kematian selama kehamilan atau dalam 
periode 42 hari setelah berakhirnya kehamilan, terjadi akibat hal yang terkait dengan kehamilan dan diperberat oleh kehamilan maupun penanganan dalam kehamilan, namun bukan disebabkan oleh kecelakaan atau cedera. Setiap ibu hamil menghadapi risiko terjadinya kematian, sehingga salah satu upaya menurunkan tingkat kematian ibu adalah meningkatkan status kesehatan ibu hamil sampai bersalin melalui pelayanan ibu hamil sampai masa nifas. Pemeriksaan kehamilan sangat penting dilakukan oleh semua ibu hamil untuk mengetahui pertumbuhan janin dan kesehatan ibu.

Survei Demografi dan Kesehatan Indonesia (2012) menunjukkan AKI di Indonesia masih tinggi sebesar 359 per 100.000 KH. Angka ini sedikit menurun jika dibandingkan dengan SDKI (1991) yaitu sebesar 390 per $100.000 \mathrm{KH}$. Tujuan ke-3 Sustainable Development Goals adalah kesehatan yang baik (menurunkan AKI) menjadi 102 per $100.000 \mathrm{KH}$. Mengacu dari kondisi saat ini, potensi untuk mencapai target SDGs ketiga untuk menurunkan AKI adalah offrack, artinya diperlukan kerja keras dan sungguh-sungguh untuk mencapainya (Kemenkes, 2014).

Kematian ibu tahun 2010-2012 disebabkan karena peningkatan pada kejadian preeklamsia, eklamsia dan faktor lain-lain, seperti masalah sosial, budaya, pendidikan yang kurang, hingga persoalan ekonomi. Sedangkan faktor pendarahan dan infeksi mengalami penurunan tiap tahun. Faktor penyakit jantung mengalami kenaikan pada tahun 2011, tetapi pada tahun 2012 mengalami penurunan. Dari proporsi tahun 2012, faktor preeklamsia dan eklamsia masih menjadi faktor dominan $(34.88 \%)$ penyebab kematian ibu di Jawa Timur (Dinkes Jatim, 2013).

AKI di Jatim saat ini tercatat 97.39/100.000 KH. Angka ini lebih rendah dari target perkiraan provinsi yaitu 102/100.000 KH. Daerah yang menyumbang angka AKI terbanyak adalah Surabaya, Kediri, Jombang, dan Situbondo. Kematian ibu kebanyakan karena terlambat membawa ke pusat rujukan. Faktor-faktor penyebab kematian ibu adalah masalah sosial, budaya, pendidikan yang kurang, hingga persoalan ekonomi. Namun penyebab paling banyak kematian ibu melahirkan adalah pre-eklampsia (tekanan darah tinggi saat melahirkan) dan pendarahan akibat kurang cepat dalam penanganan (Dinkes Jatim, 2014).

Dinas Kesehatan Provinsi Jawa Timur telah berupaya untuk menurunkan AKI dan mempercepat capaian SDGs dengan membentuk Forum PENAKIB (Penurunan Angka Kematian Ibu dan Bayi), pada tahun 2016 terbentuk tiga satuan tugas, yaitu Satgas Rujukan, Satgas Pelayanan Kesehatan Dasar serta Satgas Pemberdayaan Masyarakat. Masing-masing satgas akan menelaah penyebab kematian ibu dan bayi dari tiga aspek tersebut (Dinkes Jatim, 2013).

Data AKI menurut Dinas Kesehatan Kabupaten Kediri, dari sasaran 28.187 orang ibu hamil pada 2014, dengan jumlah ibu hamil risiko tinggi 5.637 (19.56\%) orang dan jumlah ibu bersalin 26.906 $(80.43 \%)$ orang, tercatat 13 kasus kematian ibu per Oktober 2014. Angka ini menurun dibandingkan dengan pada tahun 2013 sebanyak 34 kasus, dan 2012 sebanyak 37 
kasus. Adapun penyebab kematian diantaranya pendarahan, infeksi, preeklampsi, jantung dan lain-lain (Dinkes Kab. Kediri, 2015).

Tujuan penelitian untuk mengetahui faktor-faktor yang berhubungan dengan kejadian preeklamsia pada ibu hamil di Kabupaten Kediri Jawa Timur.

\section{METODE PENELITIAN}

Desain penelitian ini merupakan jenis penelitian kuantitatif dengan menggunakan case control study, dengan pendekatan case control study pada ibu dengan preeklamsia untuk kasus dan tidak preeklamsia untuk kontrol, mengikutsertakan masyarakatnya. Waktu pelaksanaan pada bulan April 2018 di wilayah Puskesmas Binaan wilayah Kabupaten Kediri, Jawa Tengah, Indonesia. Variabel independen yang diteliti adalah umur ibu hamil, pendidikan, pekerjaan, Body Mass Index dan berat badan. Variabel dependen yang diteliti adalah preeklamsia. Teknik pengumpulan data primer dengan melakukan wawancara menggunakan kuesioner dan didukung oleh data sekunder. Analisa data yang digunakan adalah Analisis Bivariat dengan Chi Square menggunakan SPSS 22.

\section{HASIL PENELITIAN}

\section{A. Karakteristik Subjek Penelitian}

Karakteristik subjek penelitian menjelaskan distribusi masing-masing variabel.
Tabel 1. Karakteristik Subjek Penelitian

\begin{tabular}{llcc}
\hline Karakteristik & \multicolumn{1}{c}{ Kriteria } & Frekuensi & $\begin{array}{c}\text { Persentase } \\
(\mathbf{\%})\end{array}$ \\
\hline Umur Ibu & <20 tahun / > 35 tahun & 40 & 40 \\
Tingkat & 20-35 tahun & 60 & 60 \\
Pendidikan & <SMA & 49 & 49 \\
Pekerjaan & B SMA & 51 & 51 \\
& Buruh Pabrik & 4 & 4 \\
& Buruh Tani & 1 & 1 \\
& Tani & 2 & 2 \\
& IRT & 74 & 74 \\
& Swasta & 9 & 9 \\
BMI & Wiraswasta & 10 & 10 \\
& Normal & 46 & 46 \\
Paritas & Obes & 54 & 54 \\
& Primipara & 51 & 51 \\
& Multipara & 49 & 49 \\
\hline
\end{tabular}

Hasil karakteristik subjek penelitian pada tabel 1 menunjukkan bahwa dari 100 subjek penelitian memiliki distribusi yang berbeda-beda. Deskripsi variabel penelitian dijelaskan berdasarkan karakteristik, kriteria, frekuensi dan persentase (\%). Perbandingan subjek penelitian yang preeklamsia dan tidak preeklamsia, yaitu $2: 3$. Sebagian besar ibu berusia 20-35 tahun, yaitu 60 responden (60\%). Ibu hamil sebagian besar memiliki tingkat pendidikan lebih dari SMA, yaitu 51 responden (51\%), bekerja sebagai ibu rumah tangga yaitu 74 responden (74\%). Dari 100 responden sebagian besar ibu primipara yaitu 51 responden (51\%). Sebagian besar Body Mass Index ibu adalah normal yaitu 46 responden $(46 \%)$.

\section{Analisis Bivariat}

Variabel dalam penelitian yaitu umur ibu, tingkat pendidikan, status pekerjaan, body mass index, paritas dan preeklamsia. Uji analisis bivariat yang digunakan adalah uji chi-square, manggunakan software SPSS. 
Tabel 2. Hasil Analisis Bivariat

\begin{tabular}{llcccc}
\hline No & $\begin{array}{c}\text { Variabel } \\
\text { Independen }\end{array}$ & $\begin{array}{c}\text { Nilai } \\
\text { OR }\end{array}$ & Nilai p & \multicolumn{2}{c}{$\begin{array}{c}\text { CI (95\%) } \\
\text { Batas } \\
\text { Atas }\end{array} \begin{array}{l}\text { Batas } \\
\text { Bawah }\end{array}$} \\
\hline 1 & Umur Ibu Hamil & 0.35 & 0.012 & 0.15 & 0.80 \\
2 & Paritas & 0.26 & 0.002 & 0.11 & 0.62 \\
3 & Body Mass Index & 1.06 & 0.870 & 0.47 & 2.38 \\
4 & Berat Badan & 0.93 & 0.869 & 0.41 & 2.09 \\
5 & Tingkat & 0.15 & $<0.001$ & 0.06 & 0.38 \\
& Pendidikan & & & & \\
6 & Status Pekerjaan & 8.66 & $<0.001$ & 3.46 & 21.65 \\
& & & &
\end{tabular}

Tabel 2 menunjukkan hasil hubungan antara variabel bebas dan variabel terikat. Dari hasil analisis bivariat menggunakan uji chi square didapatkan ada hubungan antara umur ibu hamil $(\mathrm{OR}=0.35 ; 95 \% \mathrm{CI}=0.15$ to $0.80 ; \mathrm{p}=0.012)$, paritas $(\mathrm{OR}=0.26 ; 95 \% \mathrm{CI}=0.11$ to 0.62 ; $\mathrm{p}=0.002)$, tingkat pendidikan $(\mathrm{OR}=0.15$; 95\% $\mathrm{CI}=0.06$ to $0.38 ; \mathrm{p}=<0.001)$ dan pekerjaan $(\mathrm{OR}=8.66 ; 95 \% \mathrm{CI}=3.46$ to 21.65; $\mathrm{p}=<0.001)$ dengan preeklamsia. Tidak ada hubungan antara BMI $(\mathrm{OR}=1.06 ; 95 \% \mathrm{CI}=0.47$ to $2.38 ; \mathrm{p}=0.870)$, $\mathrm{BB} \quad(\mathrm{OR}=0.93 ; 95 \% \quad \mathrm{CI}=0.41$ to 2.09 ; $\mathrm{p}=0.869$ ), dengan preeklamsia.

\section{PEMBAHASAN}

\section{Hubungan Umur Ibu Hamil dengan Preeklamsia}

Umur individu terhitung mulai saat dilahirkan sampai saat berulang tahun. Semakin cukup umur, tingkat kematangan dan kekuatan seseorang akan lebih matang dalam berpikir dan bekerja (Santoso, 2009). Dengan bertambahnya umur seseorang maka kematangan dalam berpikir semakin baik, sehingga akan termotivasi dalam pemeriksaan kehamilan untuk mencegah komplikasi pada masa persalinan. Umur risiko tinggi $(<20$ tahun atau $\geq 35$ tahun), menunjukkan bahwa kebanyakan ibu hamil yang muda dan ibu hamil yang tua, pada kehamilan yang ibunya masih usia muda < 20 tahun kebanyakan mereka kurang informasi terhadap pelayanan ANC, sehingga mereka banyak mengabaikan tentang pelayanan ANC. Selain itu, ibu yang berumur lebih dari $>35$ tahun sudah mulai paham tentang kehamilan pertama.

Optimalnya pelaksanaan ANC difokuskan untuk mengetahui komplikasi yang terjadi pada kehamilan kembar dan juga kehamilan pada anak kedua atau lebih (Bricker, 2014 and Ling et al, 2011). Apabila ibu hamil tidak terkena komplikasi kehamilan maka untuk kehamilan berikutnya ibu biasanya mengabaikan untuk melakukan pemeriksaan ANC, sehingga menimbulkan adanya komplikasi dalam kehamilan.

\section{Hubungan Paritas dengan Preeklamsia}

Ditinjau dari jumlah persalinannya, ibu yang mengalami preeklamsi didominasi oleh primipara, yaitu persalinan pertama kalinya, sedangkan untuk multipara didominasi oleh ibu yang tidak mengalami preeklamsi. Faktor yang mempengaruhi preeklamsia adalah frekuensi primigravida lebih tinggi bila dibandingkan dengan multigravida, terutama primigravida muda (Phillimore, 2016 and Pomerai, 2017). Persalinan yang berulang-ulang akan mempunyai banyak risiko terhadap kehamilan, telah terbukti bahwa persalinan kedua dan ketiga adalah persalinan yang paling aman (Obamiro, 2010).

3. Hubungan Body Mass Index dan Berat Badan dengan Preeklamsia

Selanjutnya obesitas juga mempengaruhi penyebab kejadian preeklampsia pada ibu bersalin, wanita 
dengan indeks massa tubuh yang lebih besar dari 30 pada awal kehamilan cenderung menderita preeklampsia.15 Perkiraan peningkatan risiko preeklampsia sebelum kehamilan menurut Robson adalah 2,5 kali lipat, sedangkan pada saat pemeriksaan antenatal meningkat 1,5 kali lipat. Angka kejadian ibu bersalin yang mengalami preeklampsia dengan obesitas ini rendah. Analisis data menunjukkan bahwa separuh peningkatan risiko perkembangan preeklampsia berkaitan dengan puncak respon radang yang berhubungan dengan IMT yang tinggi dan kenaikan kadar lipid darah yang berhubungan dengan obesitas. Kondisi preeklampsia ini terjadi karena berkurangnya aliran darah ke organ ibu maupun janin. Kehilangan berat badan sebelum kehamilan dapat mengurangi risiko preeklampsia, tapi wanita tidak harus menghilangkan berat badan selama kehamilan.

Untuk obesitas dengan kejadian preeklampsia, berbeda dengan teori yang diungkapkan bahwa kegemukan (obesitas) disamping menyebabkan kolesterol tinggi dalam darah juga menyebabkan kerja jantung lebih berat, oleh karena jumlah darah yang berada dalam badan sekitar $15 \%$ dari berat badan, maka makin gemuk seorang makin banyak pula jumlah darah yang terdapat di dalam tubuh yang berarti makin berat pula fungsi pemompaan jantung. Sehingga dapat menyumbangkan terjadinya preeklampsia.

\section{Hubungan Tingkat Pendidikan dengan Preeklamsia}

Pengetahuan ibu hamil yang tinggi akan pemeriksaan kehamilan memberikan sumbangan pada pencapaian target kunjungan pemeriksaan kehamilan. Pengetahuan ibu hamil tentang pemeriksaan kehamilan bisa didapat dari pengalaman yang sebelumnya atau dari pengalaman keluarga dan juga tetangga. Pengetahuan ibu hamil tentang pemeriksaan kehamilan dapat dipengaruhi oleh beberapa faktor diantaranya tingkat pendidikan, sosial ekonomi, lingkungan dan faktor dari dalam diri ibu sendiri. Pengetahuan ibu hamil dapat ditingkatkan dengan berbagai cara misalnya dengan penyuluhan ataupun pendekatan individu lewat kader-kader terlatih. Namun tidak semua ibu hamil akan mau diberi penyuluhan tentang pentingnya pemeriksaan kehamilannya.

Seseorang yang tidak mempunyai pengetahuan tentang pentingnya pemeriksaan kehamilan, kemungkinan besar pada kehamilannya terdapat masalah dan komplikasi yang bisa menyebabkan kesakitan ataupun kematian bagi ibu dan bayi. Oleh karena itu pengetahuan ibu sangatlah penting untuk menunjang kesejahteraan ibu dan janin selama masa kehamilan.

\section{Hubungan Status Pekerjaan dengan Preeklamsia}

Pengalaman tidak selalu berwujud suatu hal yang pernah dialami seseorang, tetapi biasa berawal dari mendengar atau melihat. Pada saat mendengar dan melihat tersebut kadang-kadang ada kata-kata bahwa ANC itu memang penting, tetapi tidak ANC juga tidak maslaah, seperti yang dialami istri orang tersebut. Hal tersebut bisa mempengaruhi pengetahuan yang telah didapat menjadi tidak terlaksana dalam wujud perilaku. 
Tingkat kemampuan seseorang untuk memenuhi kehidupan berbeda-beda. Secara sosial ekonomi, yang tinggi mempunyai kecenderungan untuk selalu menimba ilmu pengetahuan dan melaksanakannya. Berbeda dengan tingkat sosial ekonomi yang rendah, walaupun pengetahuan baik, tetapi saat pemeriksaan ANC tidak mempunyai uang kemungkinan orang tersebut akan minder dalam memeriksakan istrinya. Jarak dan transportasi sangat mempengaruhi perilaku seseorang, walaupun pengetahuannya baik akan ANC apabila jaraknya dan transportasi sulit, memungkinkan akan membuat motivasi untuk ANC berkurang sehingga terjadi tidak berkunjung untuk ANC dan banyak faktor lain yang mampu menghalangi pengetahuan seseorang tentang perilaku ANC khususnya dalam pelaksanaannya.

\section{KESIMPULAN DAN SARAN}

Ada hubungan antara umur ibu hamil dengan preeklamsia dengan hasil statistik $(\mathrm{OR}=0.35 ; 95 \% \mathrm{CI}=0.15$ to 0.80 ; $\mathrm{p}=0.012$ ), Ada hubungan antara paritas dengan preeklamsia dengan hasil statistik (paritas $(\mathrm{OR}=0.26 ; 95 \% \mathrm{CI}=0.11$ to 0.62 ; $\mathrm{p}=0.002$ ) Ada hubungan Tingkat pendidikan dengan preeklamsia dengan hasil statistik $(\mathrm{OR}=0.15 ; 95 \% \mathrm{CI}=0.06$ to $0.38 ; \mathrm{p}=<0.001)$ Ada hubungan pekerjaan dengan preeklamsia dengan hasil statistik ( $\mathrm{OR}=8.66 ; \quad 95 \% \quad \mathrm{CI}=3.46 \quad$ to 21.65 ; $\mathrm{p}=<0.001)$, Tidak ada hubungan Body Mass Index dan Berat Badan dengan Preeklamsia dengan hasil statistik ( $(\mathrm{OR}=1.06 ; 95 \%$ $\mathrm{CI}=0.47$ to $2.38 ; \mathrm{p}=0.870), \mathrm{BB}(\mathrm{OR}=0.93$; $95 \% \mathrm{CI}=0.41$ to $2.09 ; \mathrm{p}=0.869$ ), Dengan demikian dapat di sarankan bahwa Ibu hamil lebih meningkatkan periksa kehamilannya sesuai dengan prosedur yang sudah ditentukan, agar risiko kehamilan bisa diketahui sejak dini. Partisipasi ibu hamil perlu ditingkatkan dalam hal perencanaan dan evaluasi hasil, diantaranya dengan mengikuti penyuluhan dan program kelas ibu hamil yang diadakan oleh petugas kesehatan, dengan tujuan untuk meminimalisir faktor- faktor resiko kehamilan.

\section{DAFTAR RUJUKAN}

Dinas Kesehatan Provinsi Jawa Timur. 2013.

Dinas Kesehatan Provinsi Jawa Timur .2014

Dinas Kesehatan Kabupaten Kediri .2015

Kementerian Kesehatan Republik Indonesia. 2015

Kementerian Kesehatan Republik Indonesia 2014

Kementerian Kesehatan RI. Kesehatan dalam Kerangka Sistainable Development Goals (SDG'S). Jakarta: Kementerian Kesehatan RI; 2015.

Badan Pusat Statistik, Depkes RI. Survei Demografi dan Kesehatan Indonesia 2012. Jakarta: BPS; 2013

Bricker, L. 2014. Optimal antenatal care for twin and triplet pregnancy: The evidence base. Journal Best Practice and Reserach Clinical Obstetrics and Gynaecology, 28.

Santoso, H dan Ismal, A. 2009. Memahami Krisis Usia Lanjut. Jakarta: Gunung Mulia. 
122 Jurnal Terpadu Ilmu Kesehatan, Volume 7, No 2, November 2018, hlm 101-221

Obamiro, Jk. 2010. Queuing theory and patient satisfaction: an overview of terminology and application in antenatal care unit. Petroleum-Gas University of Ploiesti, 1

Phillimore, J. 2016. Migrant maternity in an era of superdiversity: New migrant's access to, and experience of, antenatal care in the West Midlands, UK. Journal Social Science and Medicine, 148.

Pomerai, KW. 2017. An investigation of antenatal care patients satisfaction with health services in Mberengwa District Midlands Province. 2014. Quality in Primay Care, 25(1).

World Health Organization. Maternal Mortality. In: Reproduction Health and Research, editor. Geneva: World Health Organize. 